\title{
A FRUIÇÃO LITERÁRIA NA LITERATURA INFANTIL AFRICANA
}

\author{
Débora Cristina de Araujo (UFES)* \\ https://orcid.org/0000-0001-8442-3366 \\ Thiara Cruz de Oliveira (UFES)** \\ https://orcid.org/0000-0003-4455-2037
}

\section{RESUMO}

A literatura infantil africana que vem adentrando no mercado editorial brasileiro tem fomentado um campo de análise sobre suas características e tendências. Interessado nesse movimento analítico, o presente artigo teve como objetivo analisar o caráter fruitivo das obras "Sulwe", de Lupita Nyong'o (2019), e "Ombela: a origem das chuvas", de Ondjaki (2014). O conceito de fruição relaciona-se à dinamicidade entre o texto literário, seu público e o processo de mediação (OBERG, 2014). Nessa perspectiva, na análise realizada foi possível identificar e realçar elementos da fruição, no plano verbal, em duas narrativas que abordam temas de valorização da identidade e cultura africana. Isso também contribuiu para evidenciar a importância de tais obras para a formação literária do público brasileiro, em especial das crianças, já que apresentam perspectivas mais positivas do que em momentos anteriores da literatura infantil disponível no Brasil.

Palavras-chave: Literatura infantil africana. Fruição literária. Sulwe. Ombela.

\section{ABSTRACT \\ LITERARY ENJOYMENT IN AFRICAN CHILDREN'S LITERATURE}

The African children's literature that has been entering the Brazilian publishing market has fostered a field of analysis on its characteristics and trends. It is interested in this analytical movement that the present article aimed to analyze the fruitive character of the works "Sulwe", by Lupita Nyong'o (2019), and "Ombela: the origin of the rains", by Ondjaki (2014). The concept of literary enjoyment is related to the dynamics between the literary text, its audience and the mediation process (OBERG, 2014). In this perspective, in the analysis carried out it was possible to identify and highlight elements of enjoyment, on the verbal plane, in two narratives that address themes of valorization of African identity and culture. This also contributed to highlight the importance of such works for the literary formation of the Brazilian public, especially for children,

Doutora em Educação (UFPR). Professora de Educação das Relações Étnico-Raciais na Universidade Federal do Espírito Santo e nos Programas de Pós-Graduação do Centro de Educação (PPGMPE e PPGE-Ufes). E-mail: debora.c.araujo@ufes.br

** Mestra em Letras (UFES). Revisora de textos no Serviço Nacional de Aprendizagem Comercial (Senac-ES).E-mail: cruzthiara@ gmail.com 
since they present more positive perspectives than in previous moments of children's literature available in Brazil.

Keywords: African children's literature. Literary enjoyment. Sulwe. Ombela.

\section{RESUMEN}

\section{LA FRUICIÓN LITERARIA EN LA LITERATURA INFANTIL AFRICANA}

La literatura infantil africana que ha entrado en el mercado editorial brasileño ha propiciado un campo de análisis sobre sus características y tendencias. Con la intención de contribuir a este movimiento analítico que el presente artículo tuvo como objetivo analizar el carácter fruición literaria de las obras "Sulwe", de Lupita Nyong'o (2019), y “Ombela: el origen de las lluvias”, de Ondjaki (2014). El concepto de fruición se relaciona con la dinámica entre el texto literario, su audiencia y el proceso de mediación (OBERG, 2014). En esta perspectiva, en el análisis realizado fue posible identificar y resaltar elementos de fruición literaria, en el plano verbal, en dos narrativas que abordan temas de valorización de la identidad y cultura africanas. Esto también contribuyó a resaltar la importancia de tales obras para la formación literaria del público brasileño, especialmente para los niños, ya que presentan perspectivas más positivas que en momentos anteriores de la literatura infantil disponible en Brasil.

Palabras clave: Literatura infantil africana. Fruición literaria. Sulwe. Ombela.

Se queres saber quem sou, Se queres que te ensine o que sei, Deixa um pouco de ser o que tu és E esquece o que sabes.

Tierno Bukar (apud Amadou Hampaté Bâ)

\section{Introdução $0^{1}$}

Nos últimos anos tem sido possível identificar um relativo aumento de publicações endereçadas ao público infantil com personagens negras protagonistas, especialmente em condição de valorização da cultura africana e afro-brasileira. Sobretudo as primeiras décadas deste século evidenciam tal movimento, por meio de editoras pequenas ou em processo de consolidação no mercado, sendo a maioria delas engajadas com a luta antirracista. Tal movimento pode ser encarado como efeito de transformações sociais e educacionais, como as ações afirmativas e, em especial, as

1 A Revisão de Língua Portuguesa e normas técnicas (ABNT) deste artigo é de responsabilidade de Renan Peres Ferro. mudanças na legislação educacional brasileira ao tornar obrigatório o ensino de história e cultura afro-brasileira e africana, por meio da Lei 10.639/2003. Ainda assim, a relação entre o número de obras lançadas no mercado ano a ano e os títulos com esse protagonismo negro é desproporcional à representatividade da população negra, visto que tal categoria compõe mais de $50 \%$ da população brasileira, conforme dados do IBGE.

Considerando que a todos os grupos humanos há a possibilidade de suas representações artísticas serem de diversas maneiras e perspectivas, é justificável, então, encontrarmos características múltiplas. No entanto, é o que 
parece não acontecer quando se trata da retratação das personagens negras na produção de literatura infantil. Sobre essa discrepância, Cuti (2010, p. 93), ao analisar a literatura brasileira, observa que "[...] a população negra no Brasil é pouco representada fora dos quadros de pobreza, pois seu processo de ascensão social é invisibilizado pela ideologia racista", porém "[...] negros há em todas as camadas sociais e assim devem ser representados". Ou seja, quando a recorrência é somente, ou em grande parte, referente a espaços sociais determinados, principalmente se comparados a outros grupos humanos em um mesmo país, estamos diante de contextos de sub-representatividade. E esse tema já foi alvo de estudos diversos como os desenvolvidos por Maria Anória de Jesus Oliveira (2003) e Paulo Vinicius B. da Silva (2008), contribuindo para o fortalecimento desse debate dentro da academia.

Sob outro ponto de vista, neste artigo a proposta de investigação é analisar obras que promovem a valorização da cultura africana por meio de seus enredos, considerando a conexão entre o texto literário, o público e os processos de mediação, apresentados por Maria Silvia Pires Oberg (2014), de modo a realçar elementos da fruição. Acredita-se, com isso, na evidente importância das obras aqui analisadas para a formação literária do público leitor brasileiro, por serem capazes de contribuir com uma representação mais dinâmica da população negra e suas origens.

Essa abordagem é realizada reconhecendo o sentido político dessa produção editorial no Brasil, principalmente quando isso ocorre em bibliotecas das escolas públicas. Concordando com Aparecida Paiva (2010, p. 513) sobre o fato de que "grande parte da população brasileira tem no ambiente escolar a única possibilidade de acesso a livros (didáticos e literários)" e ainda a noção de que "[...] a maioria perde frequentemente o contato com obras quando encerra o processo de escolarização" (PAIVA, 2010, p. 513), a importância de acervos com valorização da cultura africana faz-se imprescindível. Por outro lado, os livros, como artefatos culturais, "[...] sozinhos [...] não fazem, necessariamente, o milagre da leitura" (OBERG, 2014, p. 203, grifo da autora). Tais artefatos não podem ser (e não são) os responsáveis pela superação ou perpetuação de práticas discriminatórias, mas podem contribuir para referenciarem contextos de hierarquias ou igualdades. E já que eles possuem tal potencialidade, torna-se preponderante a ampliação e aprofundamento de pesquisas acadêmicas comprometidas com a visibilidade de obras que representem, de modo qualificado, grupos humanos historicamente discriminados. Essa defesa converge com a necessidade constante de democratização da leitura, que deve ser plural também em sua diversidade humana.

Oliveira (2014) corrobora essa posição ao defender a ampliação da tessitura literária oferecida ao público leitor brasileiro:

Ao partir do pressuposto de que a literatura infantojuvenil contemporânea apresenta personagens negros não mais reduzidos a papéis secundários e/ou à inferiorização, estamos levando em conta a possibilidade de ressignificação e valorização na tessitura literária, ao delineá-los em diversos papéis e/ou espaços sociais, sem os restringir a uma África e/ou diáspora cujo império é o da pobreza, da criminalidade, das disputas e consequente desumanização (OLIVEIRA, 2014, p. 146).

Alia-se a tal perspectiva o fato de essa expansão convergir com uma formação de mundo mais altiva e sem fronteiras. É um desejo mais que imperativo para a humanidade sob pena de, em pouquíssimo tempo, nos perdemos como seres coletivos. As palavras de Eliane Debus (2017) unem-se a esse desejo quando reiteram a literatura como uma força arrebatadora:

A palavra ficcional arrebata o leitor para um tempo e espaço que não são os seus. Desse modo, ele experiencia um viver distante do seu, ao mesmo tempo tão próximo e, ao voltar desse encontro ficcional, já não é o mesmo; ele é capaz de reconfigurar seu viver (DEBUS, 2017, p. 22).

Essa autora também ressalta o quanto a ampliação do repertório literário a partir de 
uma literatura de origem africana contribui para a formação do público leitor em contexto brasileiro, por se tratar de obras capazes de oferecer enredos diferentes dos quais estamos inseridos:

Se ler o outro e sobre o outro tem importância fundamental na formação leitora do indivíduo, o contato com textos literários, que apresentam personagens em diferentes contextos, ou a existência de escritores oriundos de diferentes contextos permite uma visão ampliada de mundo (DEBUS, 2017, p. 29).

A partir dessa premissa e com o interesse de colaborar para que a visão alargada de mundo seja um componente da literatura endereçada às crianças, este artigo tem como objetivo analisar o caráter fruitivo de duas obras literárias infantis africanas que tematizam personagens negras em condição de valorização humana: "Sulwe", de Lupita Nyong'o (2019), e “Ombela: a origem das chuvas", de Ondjaki (2014). Tratase de duas obras contemporâneas que acionam elementos de resgate e de realce positivo da cultura africana, as quais podem colaborar para a aproximação do leitor com outras formas de existir, de ser e de explicar as relações humanas e seus entraves. "Sulwe" narra a história de uma menina negra que questiona o seu tom de pele e igualmente refuta ser muito escura. Ao longo da narrativa, após entender a importância que cada um tem no mundo, isto é, compreender a conexão entre cada ser, Sulwe admira e ama a própria trajetória e fisionomia. Já "Ombela” é a história das águas, salgada e doce, uma narrativa mítica que conta a origem das chuvas e, para isso, busca na sabedoria dos maisvelhos a explicação para os acontecimentos. 0 público leitor, nesse caso, passa a ter acesso a uma outra forma de pensar o mundo e seus fenômenos naturais, bem como atribui outro lugar para o velho, divergente da cultura ocidental. De forma geral, como veremos ao longo deste artigo, tais narrativas apresentam uma perspectiva positiva que ampliam o acesso do leitor ou leitora a outros contextos, o que pode potencializar a fruição literária.
Antes de prosseguirmos, cabe considerar a trajetória de Lupita Nyong'o. Ainda que a autora seja uma mulher negra nascida na diáspora (Cidade do México), reconheceremos sua produção literária como sendo africana. Grada Kilomba (2019, p. 111), em seu estudo acerca do trauma colonial, reiterado pelo racismo cotidiano, explora esse tema em profundidade, realçando o quanto as "[...] fantasias dominantes sobre 'raça' e territorialidade" atuam para negar ou expulsar as pessoas negras de seus lugares de nascimento e crescimento. É um processo de fabricação de um estrangeirismo, a partir do que ela identifica como "novas formas de racismo", responsável não mais por apelar, como em formas antigas de racismo, para noções de raça biológica ou superioridade racial, mas sim para diferenças culturais "[...] e suas incompatibilidades com a cultura nacional" (KILOMBA, 2019, p. 112). Contudo, no caso em questão, nossa intepretação é que o movimento de Nyong'o é o inverso: territorialmente ela também se localiza no continente africano, declarando publicamente ${ }^{2}$ sua identidade africana reivindicada. É possível reconhecer, nesse movimento da autora, o que Kilomba categorizou como "identificação", por meio de "[...] um sentimento de segurança interior e autorreconhecimento" (KILOMBA, 2019, p. 237)

2 Em entrevista publicada em 2018 por Mariane Morisawa, assim respondeu Lupita Nyong'o à pergunta sobre suas raízes africanas e o fato de ter nascido no México: "Bem, nasci lá, meu nome é mexicano e me remete ao país. Carregar um nome latino é prova do tipo de mulher que meus pais queriam que eu fosse quando crescesse. Eles queriam que eu fosse uma cidadã global. Outro dia estava conversando com minha mãe e perguntei: 'Mamãe, me vê voltando para o Quênia um dia?' E ela respondeu isso, que eu era uma cidadã do mundo. Era isso que ela queria, que nós pertencêssemos ao mundo. Que encontrássemos nosso lar e nosso pertencimento onde quer que fosse. Que buscássemos nosso senso de responsabilidade onde quer que estivéssemos. E acho importante reconhecer, é um tema de que Pantera Negra fala: 'Quem sou eu e quem é meu povo?' Tudo bem para mim se o México me considerar deles. Tudo certo! E o fato de os quenianos sentirem orgulho de mim significa muito também. Porque, definitivamente, profunda e culturalmente me defino como queniana. Mas também sei que parte de mim foi afetada pelo nascimento no México". Disponível em: https://veja.abril.com.br/cultura/lupitanyongo-lamenta-racismo-no-brasil-voces-podem-mais/. Acesso em: 21 jan. 2021. 
de sua história. Isso culmina num “[...] estado de descolonização; isto é, internamente não se existe mais como a/o 'Outro/a', mas como o eu. Somos eu, somos sujeito, somos quem descreve, somos quem narra, somos autoras/es e autoridade da nossa própria realidade" (KILOMBA, 2019 , p. 238, grifos da autora).

Ainda sobre o tema da produção literária infantil africana presente no Brasil e aquelas com temática da cultura afro-brasileira, estudos como os desenvolvidos por Oliveira (2014) e Debus (2017) vêm investindo em análises sobre as características dessas obras. Especialmente a segunda autora, em um exercício de interpretação dessa literatura endereçada ao público infantil, identificou as seguintes categorias: "1) literatura que tematiza a cultura africana e afro-brasileira; 2) literatura afro -brasileira; e 3) literaturas africanas" (DEBUS, 2017, p. 26). Ao se debruçar sobre elas, a autora especifica suas características, indicando que a primeira é a que se sobressai. Trata-se de uma literatura que "[...] traz como temática a cultura africana e afro-brasileira, sem focalizar aquele que escreve (a autoria), mas sim o que tematiza" (DEBUS, 2017, p. 26).

Embora essa seja a mais popularizada, a opção de abordagem neste artigo é propor análise de obras da terceira categoria (literaturas africanas) que, conforme discute Debus, possui, em sua natureza, outras subdivisões, a saber:

- Literaturas africanas de diferentes línguas (língua portuguesa, língua inglesa, língua francesa, entre outras) a partir da multiplicidade linguística do continente.

- Literaturas africanas de língua portuguesa - o recorte de pesquisa e análise pode ser demarcado pelo país (Angola, Cabo Verde, Guiné-Bissau, Moçambique, São Tomé e Príncipe), sem adentrar na especificidade da negritude dessa literatura. [...] sugere outras subcategorias, como literatura vinculada à origem oral (lenda, fábulas, entre outras) e literatura contemporaneíssima (narrativas curtas em diálogo com a ilustração) (DEBUS, 2017, p. 26).

Nosso estudo se concentra sobre a primeira subcategoria, já que as duas obras selecionadas são produções originalmente em língua inglesa (Sulwe) e em língua portuguesa (Ombela: a origem das chuvas). A noção de fruição, alvo da nossa análise sobre tais livros, parte da interpretação de Oberg (2014). A autora recorre aos estudos sobre a recepção para argumentar que a fruição literária a qual se refere em sua pesquisa se diferencia das teorias que iniciaram a discussão desse tema, principalmente sobre o foco de cada uma. Para Oberg (2014), a fruição literária não pode ser entendida apenas pelo viés da produção, com enfoque somente na autoria, como apontavam os estudos literários ocidentais realizados do Romantismo até o final do século XIX. Mas também não estava fincada na perspectiva apenas do texto ou do leitor ou leitora. Ela acrescenta que, para Jauss e Iser, por exemplo, é quem lê que fecha o ciclo da leitura, atribuindo ao texto sentidos outros daqueles produzidos pelo autor ou autora (OBERG, 2007, p. 31-38). Diante desse apontamento, Oberg recorre a Chartier para acrescentar que o contexto sociocultural a qual o leitor pertence também irá interferir na recepção, afinal o conhecimento de mundo, de outros contextos, é elemento que intensifica a compreensão do outro, bem como pode provocar a fruição literária.

Nesse sentido, Oberg (2014) reconhece a fruição literária como não linear, complexa e interconectada com quem lê a obra:

A fruição literária apresenta um caráter de gratuidade, não funcional, que implica afetos, imaginação, sentidos e também intelecto; não é apenas um fenômeno de ordem apenas sensível, nem apenas intelectual, caracterizando-se como ato cognitivo complexo e contrapondo-se, assim, às noções que comumente a identificam como mero ato sensorial, hedonista e esvaziado de sua complexidade. A especificidade do texto literário aliada às articulações necessárias à apropriação e reconstrução de sentidos torna a fruição literária um processo no qual interagem tanto aspectos textuais particulares, como aspectos cognitivos, próprios do sujeito e relacionados a mediações de ordem histórica e cultural (OBERG, 2014, p. 204-205). 
Não se trata mais de pensar em uma leitura linear que ora privilegia o autor, o texto, ora o leitor, ou ainda a mediação, mas de uma engrenagem que envolve subjetividade, estética, forma e conteúdo. Portanto, a fruição literária "implica capacidades variadas do fruidor, além de textos e contextos socioculturais que a viabilizem" (OBERG, 2014, p. 205). Por isso nossa aposta apoia-se em uma literatura que provoca tensões no plano canônico ou, nas palavras de Oliveira (2010), "fraturas" literárias.

A 'fratura' consiste na inserção de temas, ideias e subjetividades preteridas da chamada literatura canônica e/ou impressa em seu corpus textual tendenciosamente desqualificada ou omitida, de modo a perpetuar e hierarquizar, diga-se de passagem, a tendência marcadamente eurocêntrica em detrimento das demais, a exemplo da ascendência africana (OLIVEIRA, 2010, p. 84).

São movimentos necessários e urgentes frentes a uma tendência, cada vez mais pulsante, de reduzir a experiência literária e a formação leitora das crianças brasileiras a textos moralizantes com viés conservador e racista, ao perseguir e recolher obras com mitologias africanas ${ }^{3}$, por exemplo. É considerável que a arte literária subverta tais ações com vistas a se manter como expressão cultural de um povo e de uma história.

Se os livros têm espíritos que neles dormem e se é preciso abri-los para despertar esses espíritos, podemos dizer que os livros estão vivos se estão em movimento: se as suas páginas são abertas, folheadas e lidas. Assim, a literatura não depende apenas de quem a escreve ou daqueles que a

3 Um exemplo ocorrido em 2018 e que ganhou repercussão nacional ilustra a situação da literatura infantil no Brasil: "Em março, a escritora e educadora Kiusam de Oliveira esteve no centro de uma polêmica: seu livro Omo-Oba: Histórias de Princesas (2009), publicado pela Mazza Edições, havia sido alvo de censura. Escolhido pelo Sesi Volta Redonda (interior do Rio de Janeiro) para compor o projeto pedagógico, sofreu "questionamentos de alguns pais em relação ao conteúdo" - isto é, críticas em relação à sua temática, fundada na cultura afro-brasileira - e correu o risco de ser excluído. A reação da autora e de apoiadores nas redes sociais evitou que isso ocorresse". Disponível em: https://revistaursula.com.br/filosofia-ciencia/kiusam-deoliveira-no-brasil-ensina-se-a-ser-racista-aprende-se-aser-racista/. Acesso em: 24 jan. 2021. publicam, mas também de quem a lê - cabe ao leitor fazer o livro deixar de ser uma coisa entre as demais para se tornar verdadeiramente um objeto cultural (OBERG, 2014, p. 203).

Partiremos de uma noção de triangulação da fruição literária. Esse movimento dinâmico permite, de acordo com a autora, "[...] não apenas a renovação dos significados do texto pela leitura, como também, ao atuar como categoria integradora e estruturante dos sujeitos, cria condições para uma relação diferenciada com o conhecimento e a cultura" (OBERG, 2014, p. 205, grifos da autora). É essa relação diferenciada o nosso principal alvo ao escolhermos e buscarmos elevar características fruitivas de duas obras infantis africanas. É uma discussão eminentemente política, pois reconhece a literatura em seu contexto sociocultural e não apenas investigada "[...] a partir de sua natureza e especificidade", como analisa Maria do Rosário M. Magnani (1989, p. 6) acerca de uma tendência de estudos do campo da literatura que "[...] se baseia numa noção atemporal e a-histórica dessa qualidade intrínseca do literário" (MAGNANI, 1989, p. 6).

Ao contrário, nossa posição vincula-se aos estudos que consideram o fenômeno literário como "historicamente analisável", ou seja, tomado como "um fato social, situado na superestrutura, que mantém relações com outros elementos da superestrutura e com a infraestrutura" (MAGNANI, 1989, p. 6). Para tanto, na seção seguinte exploraremos aspectos que envolvem a complexidade da fruição em diálogo com as literaturas infantis que tematizam a cultura africana.

\section{Os sentidos de fruição literária}

Um dos cuidados no processo de discussão da fruição literária está no risco de se produzir uma visão polarizada e linear entre o que Oberg (2014) chama de três "poderes": do texto, do público leitor e das mediações. 0 primeiro deles, o "poder do texto" entende a fruição como "[...] decorrência, principalmente, da incidência 
do poder do texto sobre o leitor. Essa postura coloca no objeto estético todo o poder de provocar a fruição literária" (OBERG, 2014, p. 205). É uma atitude que requer cuidado, especialmente diante da emoção com que obras (antes escassas e agora mais presentes no mercado brasileiro) com temática da cultura africana causam. Sobretudo no público adulto - aquele responsável, prioritariamente, pela escolha e direcionamento da leitura das crianças $^{4}$ essa emoção e encantamento com obras que valorizam a cultura africana pode incidir em uma aposta desmedida sobre o poder único e exclusivo do texto, desconsiderando outros fatores envolvidos. Ou seja, se assim o fosse, seria suficiente o contato com o texto literário para que a fruição acontecesse, o que incide em “[...] uma tendência estetizante da literatura e uma visão imanentista do texto literário" (OBERG, 2014, p. 205).

Em sentido oposto está a total aposta no poder do público leitor, fazendo dele uma “[...] entidade isolada dos contextos socioculturais onde vive e atua, e a natureza e a qualidade do texto não são colocados em primeiro plano" (OBERG, 2014, p. 205). Nesse sentido, bastaria que crianças, professoras, professores, familiares e sociedade em geral estivessem "abertas/ os" a uma obra literária com temática da cultura africana ou com questão antirracista que, por si só, a fruição ocorreria. Não importaria o sentido estético e nem seu conteúdo. Essa tendência produz uma armadilha analítica, conforme Débora Araujo e Paulo Vinicius B. da Silva (2011, p. 216):

[...] algumas obras preocupadas em propor a superação do racismo, trazendo tramas com tal

4 Como nos lembra Fúlvia Rosemberg (1985, p. 30), o adultocentrismo marca a escolha dos livros destinados à formação da criança leitora: "São adultos os escritores, ilustradores, diagramadores, programadores, capistas, editores, chefes de coleção; são também adultos os agentes intermediários (críticos, bibliotecários, professores, livreiros) responsáveis pela difusão do livro junto ao comprador que também é adulto (bibliotecários, pais e parentes). Aqui, a distância entre criação e consumo é máxima, pois o público infantil, enquanto categoria social, não participa diretamente da compra do produto que consome e quase não dispõe de canais formalizados para opinar livremente sobre o livro que lê. Fala-se, nesse caso, em receptor cativo". tema, nem sempre obtêm êxito em seu objetivo, além de deixar de lado o caráter literário que toda obra infantil e infantojuvenil, sobretudo, precisam ter, sob pena de vivenciarem seus estigmas historicamente imputados e que as relegaram a práticas didatizantes e desvinculadas de qualidade estética.

0 último dos três "poderes" é a mediação, a qual "[...] defende que o poder de provocar a fruição está nas mediações" (OBERG, 2014, p. 206) e, assim, bastaria apenas a criação de uma atmosfera ou um conjunto de ações ou, ainda, "[...] que o sujeito esteja imerso em um contexto de valorização da leitura, para que se entregue ao ato de ler e de fruir o texto literário" (OBERG, 2014, p. 206). Nessa lógica, tal tendência teria êxito apenas por meio do fomento de insumos às bibliotecas escolares com obras com temática da cultura africana e afro-brasileira, sem considerar outras variáveis como o público a quem essas obras são endereçadas, o processo formativo de nossa sociedade racista, os limites e desafios da educação literária no Brasil e a qualidade das obras.

Por isso as três representam, em si mesmas, tendências limitadas ao contribuírem para dicotomias e polarizações na compreensão da fruição na formação literária das pessoas. Diferentemente, concordamos com Oberg (2014, p. 206) que a fruição literária é “[...] produção, é constructo mobilizante e mobilizador de diferentes esferas do sujeito e da ordem sociocultural". E é assim, pois sua natureza é não linear e, ao contrário, gera "[...] um jogo dinâmico de tensões e de interações contínuas entre os polos do leitor, do texto literário e das mediações socioculturais - todos eles, ao mesmo tempo, sujeitos e objetos dos processos de significação" (OBERG, 2014, p. 206).

0 exercício proposto neste artigo relaciona-se a uma nuance do processo de fruição literária. Por não investigar, devido aos limites do texto, o campo da recepção e não explorar, em profundidade, o contexto de criação, não se verifica, efetivamente, esse jogo dinâmico de tensões que operam concomitantemente a não ser sob o olhar das autoras deste texto 
-, mas que oferece indícios significativos da fruição em duas obras africanas.

\section{As obras literárias e os elementos culturais}

0 registro de temas sensíveis e complexos (como o racismo, ou, em contexto brasileiro, de temas tabus como as mitologias africanas) em textos literários nem sempre é fácil e requer da autora ou autor um cuidado para não desvirtuar o sentido artístico de um enredo para uma escrita utilitária. Esse risco é muito maior na escrita para crianças, pois, munida de um sentimento adultocêntrico, a pessoa adulta tende a "ensinar" ou "transmitir" valores morais acima de qualquer projeto literário (artístico). Produzir esse tipo de literatura exige, então, demasiado cuidado para que não se caia na armadilha do recurso didatizador e moralizante, conforme defende Regina Zilberman (1987), bem como seja mantido o trabalho com a arte. Por isso é importante a ressalva de Maria Zaira Turchi (2004, p. 38): “Considerar o livro para crianças um objeto estético é reconhecer-lhe o estatuto da arte, não de obra paradidática, e perceber sua capacidade de construir um espaço textual plurissignificativo do ser humano diante do mundo".

E esse sentido plurissignificativo foi uma marcante na obra "Sulwe". Depois de refletir sobre a sua pele escura em comparação com as cores mais claras de seu pai, sua mãe e sua irmã, a menina protagonista "[...] decidiu que mudaria de dentro para fora. Passou a comer somente os alimentos mais claros e brilhantes" (NYONG'O, 2019, s/p). Ao dormir ela pediu um milagre a Deus:

'Querido Deus,

Por que eu tenho a cor da meia-noite se minha mãe tem a cor da aurora? Por favor, faça com que minha pele seja clara como a pele dos meus pais. Quero ser bonita de verdade. Não quero mais fingir que sou bonita. Quero ter o brilho do dia. Quero ter amigos. Meu Deus, se você estiver me ouvindo e puder atender ao meu pedido, quero acordar com a pele clara e radiante como o sol lá no céu. Amém' (NYONG’O, 2019, s/p).

As chances de um texto com tal caminho narrativo incidir em obviedades são muito grandes, por exemplo: de transformação efetiva da cor da pele da menina e um posterior arrependimento ao perceber que ser negra é lindo ou, ainda, de uma conformação infeliz da protagonista ao ter que, definitivamente, aceitar sua cor e "fingir que é bonita" (NYONG'O, 2019, s/p).

O percurso narrativo da obra, no entanto, supera o lugar-comum ao transpor o enredo para o campo do fantástico. Ao acordar no dia seguinte, Sulwe percebeu-se igual e passou a lançar perguntas depois de ouvir sua mãe - que havia escolhido no nome Sulwe pois significava "estrela" - explicar-lhe: "O brilho não está na pele, meu amor. Você é o brilho" (NYONG'0, 2019, s/p). As perguntas eram sobre sua autopercepção: “Como ela, com aquela pele tão escura, poderia ter brilho? Como ela poderia ser bonita se ninguém além da mãe dela via isso? Como ela poderia ser uma estrela?" (NYONG'0, 2019, s/p).

Naquela noite a menina recebe a visita de uma estrela cadente que a leva para o céu escuro, onde narra a história de duas irmãs (a Noite e a Dia) que se amavam muito, mas que não eram tratadas de modo igual, já que a Dia era chamada de amável, gentil e bonita, ao passo que a Noite era chamada de assustadora, má e feia. De tanta mágoa, a Noite abandonou a face da Terra, fazendo com que a Dia ficasse sozinha sobre as pessoas, esquentando tudo a sua volta. Esta decidiu, então, ir atrás da Noite, a fim de que ela retornasse ao seu lugar de origem e juntas continuassem, cada uma ao seu modo, ajudando o funcionamento da vida. Reencontrando a irmã, que estava magoada, Dia convenceu Noite a retornar.

[...] e as pessoas se alegraram com seu retorno.

- Precisamos dos tons mais escuros da noite para descansar profundamente. Precisamos de você para que possamos crescer, sonhar e guardar nossos segredos conosco. 
As estrelas entraram na conversa:

- O brilho não está apenas na luminosidade do dia. A luz se manifesta em todas as cores. Algumas luzes só podem ser vistas no escuro.

Dia emanava um brilho dourado, enquanto Noite resplandecia um brilho prateado, elegante e refinado sobre todas as coisas (NYONG'O, 2019, $\mathrm{s} / \mathrm{p})$.

O desenrolar da história aí, sim, assume uma posição clichê, até pelo fato de se tratar de uma narrativa fantástica. Ao ouvir Dia dizendo à Noite "Você fica ainda mais bela quando manifesta seus tons mais escuros. Nesses instantes, você expressa seu Eu verdadeiro", Sulwe decidiu que "[...] não se esconderia mais. 0 mundo era seu lugar! Escura e bela, forte e cheia de brilho" (NYONG'O, 2019, s/p).

Um aspecto que se depreende da noção de fruição não linear e não polarizada é a superação da expectativa de que a obra contemple, por si mesma, todos os anseios de uma escolha temática. Ao encerrar o enredo desta forma, eventuais críticas podem ser feitas, como o fato de a transformação interna da menina ter sido rápida na narrativa ou de ser um final feliz, por exemplo. Em outra medida, aspectos positivos podem ser identificados ao se observar que a transformação não foi tão imediata assim, pois foi construída gradativamente em sua vida, seja por meio de sua mãe (que enfatizava sua beleza e seu brilho, a começar pelo seu próprio nome), quanto pelas reflexões sobre si própria diante do espelho, o famigerado objeto de construção de auto-ódio ou de autoamor. Cabe, não tão somente ao livro, nem tão somente ao público leitor e muito menos somente à mediação a exploração da fruição.

Nesse contexto, a fruição literária se coloca como uma categoria 'entre', de interseção: é 'in-dizível', é 'inter-dita', 'só pode ser dita entre as linhas'. Mobiliza a razão e os sentidos. Envolve o natural, mas, para se constituir, necessita também do cultural, não se esgotando em nenhuma categoria em especial - é construída, portanto, nos desvãos, nas oscilações entre leitor, texto e mediações socioculturais de diferentes ordens apresentadas pelos contextos (OBERG, 2014, p. 206).
Em "Ombela: a origem das chuvas", esse processo de mobilização da razão e dos sentidos num movimento dinâmico é intensificado pela noção de deuses e deusas que vivenciam dramas humanos. A preocupação de Ombela, uma deusa, era de fazer mal aos humanos:

- Estou triste e vou chorar...

mas para que as minhas lágrimas não matem os bichos nem as pessoas que vivem na Terra, vou deixar que tenham muito sal e que alimentem todos os mares (ONDJAKI, 2014, s/p).

Seu pai explica-lhe que "[...] assim como a lua tem muitas faces, no mundo, por vezes, faz Inverno e outras vezes faz Verão. Mesmo nós, os deuses, não podemos sempre estar felizes. Se é hora de sorrir, deves sorrir. Se precisas de chorar, deves chorar" (ONDJAKI, 2014, s/p). A menina então chora tudo o que tem para chorar, mas, ao cessar, aponta um novo dilema: "Não sei se choro porque ainda estou triste ou porque gosto de olhar o mar..." (ONDJAKI, 2014, s/p).

As dúvidas que permeiam os pensamentos de Ombela é um belo exemplo do aspecto fruitivo da literatura: o que nós, leitoras e leitores, faremos desse dilema de Ombela depende da relação que estabelecemos com a cultura, com o contexto e com a capacidade de "toque" que tal drama acionará ou não em nós. Isso porque "[...] não há possibilidade de construção 'autônoma' (fora do tempo e do espaço) dos sentidos, e a fruição literária é sempre uma produção na/da/de cultura" (OBERG, 2014, p. 207).

Mas o texto continua explorando outros sentidos:

O pai de Ombela, ao saber da sua dúvida, veio falar com ela.

- Minha filha, quero que saibas mais uma coisa: as lágrimas não nascem dos olhos apenas quando estamos tristes. Existem também as lágrimas de felicidade (ONDJAKI, 2014, s/p).

Dessa forma, Ombela compreende que suas lágrimas não precisam ser só de tristeza (salgadas) e quando forem de alegria serão doces e criarão rios, lagos e lagoas. Assim: "Se essa 
chuva cai sobre o mar, Ombela está triste. Se cai sobre a terra, sobre os rios, sobre os lagos, Ombela está feliz. Dizem que Ombela teve muitas filhas... E que todas sabem fazer chover" (ONDJAKI, 2014, s/p).

Esse cuidado estético na elaboração do enredo é, como já defendido aqui, uma premissa indispensável na literatura infantil, alvo histórico e de origem, de um sentido utilitário e didático. Por isso a importância da valorização da fruição literária, ainda mais em obras que sofrem - pelo racismo literário - cerceamentos, boicotes e resistências. Embora o argumento estético também possa servir para "escamotear o racismo subjacente" (CUTI, 2010, p. 92), reconhecer e ressaltar potencialidades em obras que acionam o sentido fruitivo de um texto é imprescindível. "Os textos literários - como, de resto, todos os objetos estéticos -, apesar de poderem servir a finalidades didáticas, apresentam caráter que transcende ao dos objetos funcionais e é exatamente em sua gratuidade, em seu não ensinar, que eles nos ensinam" (OBERG, 2014, p. 207, grifos da autora).

E esses ensinamentos ganham maior corporeidade quando expandem nossos conhecimentos para além do estereótipo, do que consideramos ser a verdade. É um salto que se lança para o novo e, no caso da literatura infantil africana em contexto brasileiro, o novo é também re-conhecimento da tradição, não mais uma tradição canônica e cristalizada e ocidentalizada, mas uma rememoração de algo que ficou esquecido e que agora é possível recuperá-lo. Tal noção é mais bem expressa pelos povos akan ao utilizarem ideogramas (de nome adinkra) para expressar ditames ou fábulas que representam conceitos filosóficos. Tomando como exemplo esses ideogramas do povo akan, o melhor adinkra que retrata esse exercício e desejo de recuperação da tradição africana por meio de uma literatura infantil contemporânea é o Sankofa, assim definido por Elisa Larkin Nascimento (2008, p. 32):

'Nunca é tarde para voltar e apanhar aquilo que ficou para trás. Sempre podemos retificar os nossos erros'. O ideograma é uma estilização do passado que vira a cabeça para trás e representa o mesmo conceito do banco do rei e do bastão do linguista [outros dois adinkras]: a sabedoria de aprender com o passado para construir o presente e o futuro.

E especialmente a tradição oral, marca recorrente na literatura infantil africana, se faz presente em "Ombela: a origem das chuvas" já nas primeiras palavras do texto: "Dizem os mais-velhos que a chuva nasceu da lágrima de Ombela, uma deusa que estava triste" (ONDJAKI, 2014, s/p). E depois no desfecho da história: "Dizem os mais-velhos que a chuva é sinal de que Ombela está a chorar" (ONDJAKI, 2014, s/p). Hampaté Bâ (2010) discutiu a oralidade, realçando sua importância para a tradição africana:

Quando falamos de tradição em relação à história africana, referimo-nos à tradição oral, e nenhuma tentativa de penetrar a história e o espírito dos povos africanos terá validade a menos que se apoie nessa herança de conhecimentos de toda espécie, pacientemente transmitidos de boca a ouvido, de mestre a discípulo, ao longo dos séculos. Essa herança ainda não se perdeu e reside na memória da última geração de grandes depositários, de quem se pode dizer são a memória viva da África (HAMPATÉ BÂ, 2010, p. 167).

Para o autor, a oralidade é o que caracteriza a tradição africana, ainda que existam no continente africano várias culturas e suas particularidades. Não se trata de pensá-lo como uma unidade coesa, mas de compreender a oralidade como uma marca histórica das culturas africanas. Raul Ruiz de Asúa Altuna (2014, p. 38) acrescenta que "[...] a tradição oral é, assim, a biblioteca, o arquivo, o ritual, a enciclopédia, o tratado, o código, a antologia poética e proverbial, o romanceiro, o tratado teológico e a filosofia". Esse elemento tradicional vai passando de geração em geração e encontra nos mais-velhos os guardiões culturais. Trata-se de culturas cuja palavra oral tem valor de documento escrito ${ }^{5}$, afinal a palavra no

5 Como nos lembra Henrique Cunha Junior (2007, p. 1): “A utilização da escrita no continente africano é um fenômeno 
“[...] escrito ou oral, no fim não é mais que testemunho humano, e vale o que vale o homem" (HAMPATÉ BÂ, 1982, p. 168).

Assim, com a finalidade de compreender essa fruição literária nas produções literárias infantis africanas, exige-se, em primazia, conhecer elementos culturais africanos, sobretudo a tradição oral, pois ela "[...] é a grande escala da vida, e dela recupera e relaciona todos os aspectos" (HAMPATÉ BÂ, 2010, p. 169).

Ademais, outro elemento idiossincrático a muitas culturas africanas é a força vital. Em "Sulwe", quando a personagem Dia fica constantemente na Terra e Noite vai embora, há o rompimento de energias importantes para todos os seres. Uma conexão foi desfeita, de modo que a dinâmica da vida foi alterada: "Dia começou a sentir muita falta da irmã. Assim como todo mundo" (NYONG'O, 2019, s/p). Para compreender essa relação, é indispensável entender que, para algumas culturas africanas, o mundo está organizado a partir de energias conectadas que garantem o dinamismo da vida, como analisa Fábio Leite (1997). Ou seja, essa força “[...] refere-se àquela energia inerente aos seres que faz configurar o ser-força ou força-ser, não havendo separação possível entre as duas instâncias, que, dessa forma, constituem uma única realidade" (LEITE, 1997, p. 104), formando assim uma corrente vital, em que cada ser contribui

histórico presente em todas as regiões do continente. A criação de escritas originais, a adaptação de escritas de outras regiões e mesmo a difusão da escrita com caracteres árabes, em árabe e em línguas nacionais sempre existiu na África, anterior à difusão pelas regiões da Europa. Formas de escritas em uso na África chegaram ao Brasil através dos imigrantes forçados, africanos aqui escravizados. Entretanto, apesar da longa tradição da escrita na cultura africana, os africanos são apresentados na cultura brasileira como povos ágrafos. Esta ideia de suposta falta de escrita é representada e confundida na sociedade brasileira como um suposto atraso cultural e ausência de civilização". Tal apontamento do autor só realça a multiplicidade do continente africano e a necessidade de realizarmos análises cuidadosas sob pena de incorrermos em generalizações ou atribuições de novos estereótipos. É o que alerta a socióloga Oyèrónké Oyěwùmí (2004, p. 9): "Análises e interpretação de África devem começar a partir de África. Significados e interpretações devem derivar da organização social e das relações sociais, prestando muita atenção aos contextos culturais e locais específicos". para a manutenção das vibrações positivas (ou negativas).

Desse modo, tanto a oralidade quanto a força vital, dentre outros (LEITE, 1997) ${ }^{6}$, são elementos necessários para a articulação da fruição literária quando se trata de formação de leitores e leitoras a partir de textos que abordam as culturas africanas.

\section{Considerações finais}

Tanto “Sulwe”, de Lupita Nyong'o (2019), quanto "Ombela: a origem das chuvas", de Ondjaki (2014), são apenas dois bons exemplos de possibilidades de leitura que dialogam com uma perspectiva de valorização da cultura africana. Existem muitas outras abordagens que caminham neste sentido, já que o mercado editorial tem correspondido à demanda do público leitor que reivindica uma literatura mais plural, e algumas editoras têm se posicionado atuantes na luta antirracista. Neste artigo, buscamos, por meio do conceito de fruição literária (OBERG, 2014), que extrapola o texto, o leitor/leitora e a mediação, marcar a importância do público leitor, sobretudo crianças, ter acesso às produções literárias que realçam de forma positiva as culturas africanas. Dessa maneira, cria-se um campo fértil para possíveis abordagens que retiram a personagem negra do plano secundário, bem como incrementam discussões em combate ao racismo.

Para Magnani (1989), a literatura ganha, assim, contornos políticos na atuação social. Além disso, Oberg acrescenta que:

[...] é uma forma cultural diferenciada e única; é compreensão, indagação, reflexão, construção e desconstrução de significados, que exige atuações específicas por parte do leitor na sua apropriação - ao contrário de outras formas textuais calcadas na univocidade e na transparência, o signo literário alimenta-se da ambiguidade,

6 Fábio Leite (1997), no texto Valores Civilizatórios em sociedades negro-africanas, elenca como valores civilizatórios os seguintes elementos: força vital, palavra (oralidade), homem, socialização, morte, ancestrais, família, produção e poder. Cada um possui concepções que, certamente, destoam da lógica cartesiana ocidental. 
da opacidade, da plurissignificação, da mesma forma que pede modos de aproximação compatíveis com tal natureza para ser experimentado em suas múltiplas possibilidades (OBERG, 2014, p. 204).

Entende-se, portanto, que o texto literário pode, mesmo na "gratuidade" anunciada por Oberg (2014), exercer a função de deslocar realidades, contribuindo de maneira robusta para uma formação integral de leitores, por meio de elementos culturais diversos, que fogem a uma estereotipia histórica atribuída às culturas africanas. Conclui-se que, embora não tenha o poder único de transformação social, o texto literário que tematiza as culturas africanas pode romper com a atual condição de leitura e, com isso, criar possibilidades e garantir que leitores e leitoras tenham, de fato, a democratização da leitura no contexto brasileiro.

\section{REFERÊNCIAS}

ALTUNA, Pe. Raul Ruiz de Asúa. Cultura tradicional bantu. Portugal: Paulinas, 2014.

ARAUJO, Débora Oyayomi Cristina de; SILVA, Paulo Vinicius Baptista da. Diversidade étnico-racial e a produção literária infantil: análise de resultados. In: BENTO, Maria Aparecida Silva (org.). Educação infantil, igualdade racial e diversidade: aspectos políticos, jurídicos, conceituais. São Paulo: Centro de Estudos das Relações de Trabalho e Desigualdades - CEERT, 2012, p. 194-220.

CUNHA JR., Henrique. O Etíope: Uma escrita africana. Educação Gráfica, Bauru, v. 11, p. 1-10, 2007. Disponível em: http://www.educacaografica. inf.br/wp-content/uploads/2011/06/01_0_ Etiope.pdf. Acesso em: 15 jun. 2021.

CUTI (Luiz Silva). Literatura negro-brasileira. São Paulo: Selo Negro, 2010.

DEBUS, Eliane. A temática da cultura africana e afro-brasileira na literatura para crianças e jovens: lendo Joel Rufino dos Santos; Rogério Andrade Barbosa, Júlio Emílio Brás, Georgina Marins. Florianópolis: NUP/CED/UFSC, 2017.

HAMPATÉ BÂ, Amadou. A tradição viva. In: KIZERBO, Joseph (Ed.). História geral da África, I: Metodologia e pré-história da África. 2. ed. rev. Brasília: UNESCO, 2010, p. 167-212.
KILOMBA, Grada. Memórias da plantação: episódios de racismo cotidiano. Tradução de Jess Oliveira. 1. ed. Rio de Janeiro: Cobogó, 2019.

FABIO, Leite. Valores civilizatórios em sociedades negro-africanas. África: Revista do Centro de Estudos Africanos. USP, S. Paulo, v. 18-19, n. 1, p. 103-118, 1997.

MAGNANI, Maria do Rosário M. Leitura, literatura e escola: sobre a formação do gosto. São Paulo: Martins Fontes, 1989. (Coleção texto e linguagem)

NASCIMENTO, Elisa Larkin. Sankofa: significados e intenções. In: NASCIMENTO, Elisa Larkin (org.). A matriz africana no mundo. São Paulo: Selo Negro, 2008, p. 29-54. (Sankofa: Matrizes africanas na cultura brasileira; 1 )

NYONG'O, Lupita. Sulwe. Ilustrações de Vasti Harrison; tradução de Rane Souza. 1. ed. Rio de Janeiro: Rocco Pequenos Leitores, 2019.

OBERG, Maria Silvia Pires. Informação e significação: a fruição literária em questão. Doutorado (Ciência da Informação) - Escola de Comunicações e Artes, Universidade de São Paulo, 2007.

OBERG, Maria Silvia Pires. Onde estão as chaves? Considerações sobre a formação do leitor e a fruição literária. In: BELMIRO, Célia Abcalil et al. Onde está a literatura? Seus espaços, seus leitores, seus textos, suas leituras. Belo Horizonte: Editora UFMG, 2014. p. 203-209.

ONDJAKI. Ombela: a origem das chuvas. Ilustrações de Rachel Caiano. Rio de Janeiro: Pallas Mini, 2014.

OLIVEIRA, Maria Anória de Jesus. Negros personagens nas narrativas literárias infanto-juvenis brasileiras: 1979-1989. Dissertação (Mestrado em Educação) - Universidade do Estado da Bahia: Salvador, 2003.

OLIVEIRA, Maria Anória de Jesus. Literatura infanto-juvenil contemporânea no Brasil e em Moçambique: tecendo negritudes. Itabaiana: GEPIADDE, ano 4, v. 7, p. 75-92, jan-jun/2010.

OLIVEIRA, Maria Anória de Jesus. África e diásporas na literatura infantojuvenil no Brasil e em Moçambique. Salvador: EDUNEB, 2014.

OYĚWÙMÍ, Oyèrónké. Conceituando o gênero: os fundamentos eurocêntricos dos conceitos feministas e o desafio das epistemologias africanas. Tradução para uso didático de: OYĚWÙMÍ, Oyèrónké. Conceptualizing Gender: The Eurocentric Foundations of Feminist Concepts and the challenge of African Epistemologies. African 
Gender Scholarship: Concepts, Methodologies and Paradigms. CODESRIA Gender Series. v. 1, Dakar, CODESRIA, 2004, p. 1-8 por Juliana Araújo Lopes. Disponível em: https://ayalaboratorio.files. wordpress.com/2019/06/conceito-genero.pdf. Acesso em: 15 jun. 2021.

PAIVA, Aparecida. Reflexões sobre políticas públicas brasileiras de leitura. In: FRADE, Isabel Cristina Alves da Silva et al. (orgs.). Convergências e tensões no campo da formação e do trabalho docente. Belo Horizonte: Autêntica, 2010, p. 503-533. (Didática e prática de ensino).

SILVA, Paulo Vinicius Baptista da. Relações raciais em livros didáticos: estudo sobre negros e brancos em livros de Língua Portuguesa. Belo
Horizonte: Autêntica, 2008. (Coleção Cultura Negra e Identidade)

TURCHI, Maria Zaira. O estético e o ético na literatura infantil. In: CECCANTINI, João Luís C. T. (org.). Leitura e literatura infantojuvenil: memória de Gramado. São Paulo: Cultura Acadêmica; Assis: ANEP, 2004, p. 269-285.

ZILBERMAN, Regina. A literatura infantil na escola. 6. ed. São Paulo: Global, 1987.
Recebido em: 22/02/2021

Aprovado em: 27/05/2021

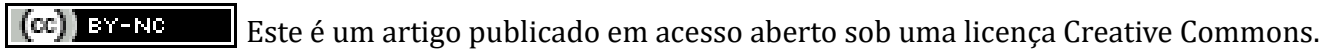

